\title{
Computer Network Curriculum Reform-Aiming at Cultivating Versatile Talents
}

\author{
Meng Wang and Fanzhi Kong* \\ College of Medical Information Engineering, JiNing Medical University, RiZhao, ShanDong, China
}

\begin{abstract}
Recently, an increase of employment pressure on the graduates has made higher demands on talents cultivation in colleges and universities. Those versatile talents with a sound theoretical basis and rich practical skills will deservedly become the objective of talents cultivation in colleges and universities, because they can gain more popularity in the society. Computer Network is the core course of computer science and it is of high practice. Taking the course of Computer Network as a backing and practical teaching reform as a breakthrough, the paper explores the approaches to foster versatile talents in computer network through reforming practical teaching system, which mainly includes construction of practical platforms, development of textbooks, and reform of practical teaching methods.
\end{abstract}

Keywords: Computer network, curriculum reform, talents cultivation, versatile talents.

\section{INTRODUCTION}

In recent years, graduates from colleges and universities have faced the increasingly severe problem of employment. One of the main reasons is irrelevance of the teaching content to the job market [1]. What has been learnt in the classroom is not what the job market needs. Therefore, in order to achieve employment, these students have to attend some training classes after they graduate [2]. Because such a problem exists in the course of Computer Network, we decide to reform the existing teaching model, placing emphasis on practical teaching. Aiming at fostering versatile talents with a sound theoretical basis, rich practical skills and creative ability, we explore the cultivation of interdisciplinary network talents through construction of practical platforms, adjustment of practical content, and reform of teaching methods. In this way, when the students graduate, they can not only gain the opportunity to further their studies with their sound theoretical basis but also apply for a decent job with their practical skills.

\section{ORIENTATION OF CULTIVATING}

The first problem that high education has to solve is what type of talents should be fostered. Correct orientation of talents cultivation can make the teaching have a more precise object, create various conditions around the object of cultivating talents, and carry out work to foster desirable talents [3]. Take a course for an example, why do we offer such a course? What abilities should this course train? What teaching objectives should the course reach? Only when we solve those problems and capture developing orientation of the course, can we well develop a course and cultivate talents.
In recent years, network has gained popularity in every field of the society and increasingly changed our lives, especially with the development of technology of Internet of things. Just for this reason, there is a great need for talents in Internet throughout the society [4]. To meet the needs of society, colleges and universities, one after another, has strengthened the cultivation of talents of network technique. Under such a circumstance, the teaching of Computer Network has consequently been given more prominence.

At present, the differences in educational levels of colleges and universities lead to a vacancy in terms of the cultivation objective of talents in computer network [5]. On one hand, as for some key universities, especially 985 or 211 project universities, they lay more emphasis on the cultivation of theoretical talents, which focuses on the teaching of network layer structure, protocol analysis, network programming, and ignore that of market-oriented techniques such as wiring, networking, and network device debugging. On the other hand, as for the higher vocational schools, they lay more stress on the cultivation of talents of high technique, so they attach importance to the proficiency in techniques which are needed by the market and conversely they ignore the teaching of network theories. As for some ordinary colleges and universities, what should they orientate their teaching objectives? For one thing, compared with $985 / 211$ project universities, ordinary colleges and universities have lower levels of staff, students and teaching resources. Therefore, it is impossible and difficult for these ordinary colleges and universities to cultivate network talents of high levels who specialize in network protocol design and analysis. For another, these ordinary colleges and universities can not limit themselves to the cultivation of technical blue collars. Based on what has been compared and analyzed, it's wise for the ordinary colleges and universities to work out a comprise formula, orientating the cultivating objective towards the cultivation of versatile talents with a sound theoretical basis and proficiency in network techniques. 


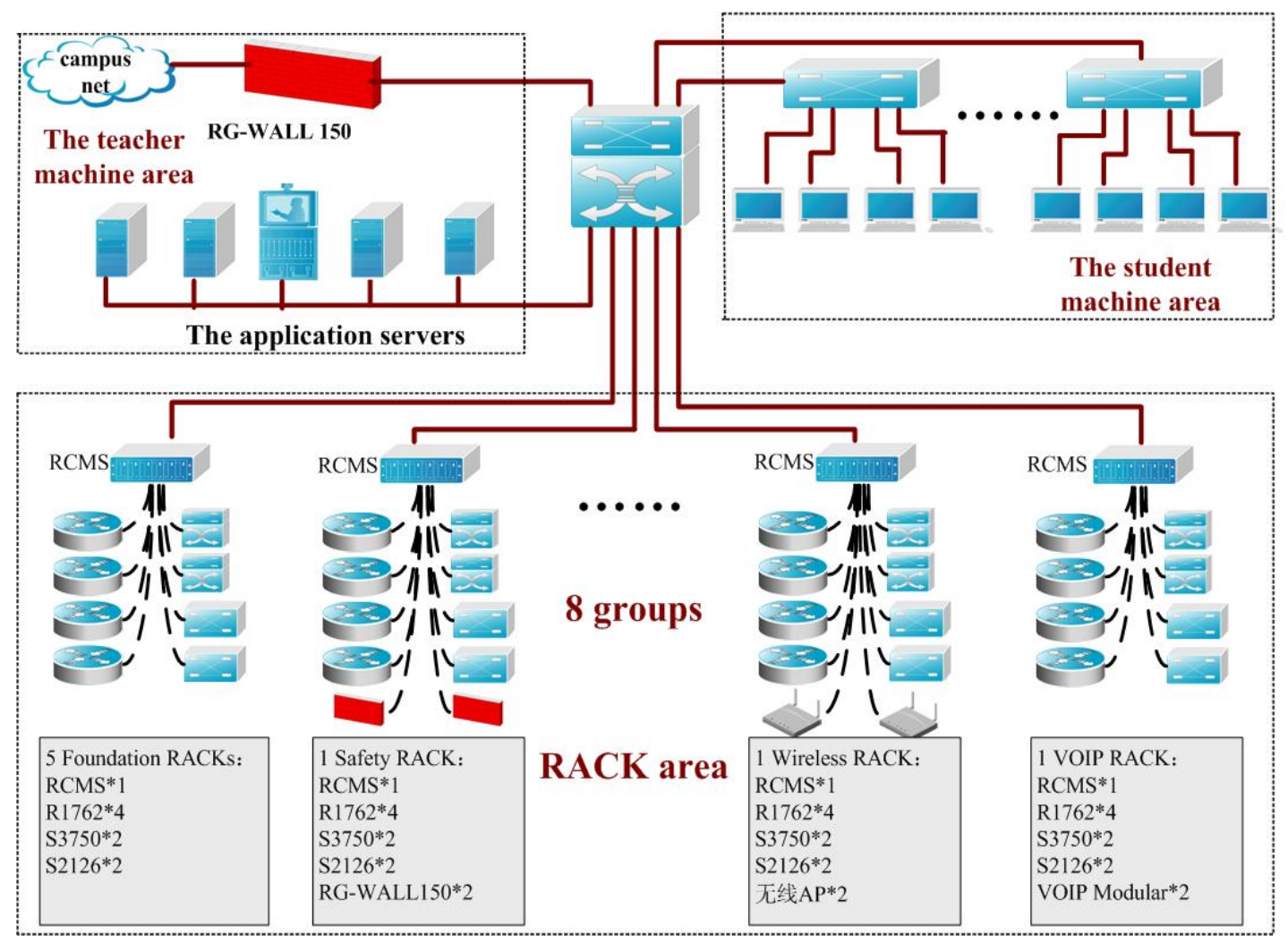

Fig. (1). Topology of network laboratory.

\section{CONSTRUCTION OF PRACTICAL PLATFORMS}

As a saying goes, a workman must sharpen his tools if he is to do his work well. A good practical platform is of necessity for the purpose of cultivation of versatile network talents. Presently, because of a great variety of computer network devices and their high price, it's difficult for most ordinary colleges and universities to construct specialized network laboratories due to lack of funds. Network practice is mainly carried out with the help of the mutational software such as NS2 and OPENT [6,7].

As an ordinary university, our university built a training base for computer network project with over 1000,000 RMB at 2008. After investigating and considering various plans, we finally adopted the solution to a network laboratory provided by RUIJIE Network Company, which is the leading supplier for network devices and solutions in this field. As the most popular one in colleges and universities, RUIJIE network laboratory solution plan is specially designed for some colleges and universities such as Huazhong University of Science and Technology, Northeast University and so on [8].

The topology of the network laboratory is shown in Fig. (1). It contains eight groups of RACK practice platforms, among which every group incorporates a set of network devices: switch, router, wireless module, security module and so on. They are governed by RCMS (RACK Control $\&$ Management Server). Students can access and manage all network devices on the practice platform by accessing RCMS. Each practice platform can independently finish all the practice in switch and route and also it can accomplish practice relevant to wireless and security.
The establishment of the laboratory created us a favorable practical teaching environment. In a real network environment, students can intuitively and extensively get familiar with various network devices and application environments through designing, building, configuring and debugging the network; they can also deepen their understanding of theoretical knowledge such as principles of network, protocol, and standards and so on.

\section{DEVELOPMENT OF TEXTBOOKS}

Currently, there are a great many theoretical textbooks about computer network but comparatively less practical textbooks. Most of all, there are particularly least practical textbooks with practice projects of high operability, orientating towards some given network devices and practice environment. In this situation, on the basis of rich accumulated materials of several years, the research group published its own practical textbook-Practice of Computer Network, which possesses two striking features.

Firstly, from the viewpoint of guiding ideology, under the guidance of project-based teaching, the textbook transforms knowledge in traditional discipline system into several teaching projects. Guided by teachers, students learn through finishing each complete working project, which can consequently cultivate students' creative ability and practical ability. The key content in the book is to provide learning resources, establish cooperative learning environment and give students enough freedom to creatively finish practical projects. Therefore, in the process of editing this book, we highlighted the background knowledge of projects. All background knowledge related with a given project is provided. Teachers scientifically divide students into several groups, 
making them actively participate, cooperatively learn and comprehensively use the provided background knowledge to design projects.

Secondly, from the point of view of content, combining with the course orientation of talent cultivation and the reality of network application, this book separately designs twenty-four practice projects, which not only cover the major content of computer network, but also contains the latest content such as integrated wiring, Internet of things, and exercises for graduate entrance exam in advanced projects. From the point of view of structure, it forms a system of 244 : 2 stands for two-level system with chapters and projects; 4 stands for four chapters: basic training (four projects), network technique training (eight projects), server configuration (four projects) and advanced project training (eight projects); the other 4 stands for four constituents of every projects: object of the project, background knowledge, project design and project evaluation.

The content of this textbook is shown in Table 1. We have used this textbook for almost two years, and it is proved that this textbook can completely meet the needs of teaching and it fills the vacancy in practical textbooks. At present, this textbook has been used by many colleges and universities in our country, which further confirms the universality and scientific of the textbook.

\section{REFORM OF TEACHING METHODS}

The advanced practical platform and practice-targeting textbook offer us premises to cultivate versatile network talents according to the above orientation. We need to reform the previous teaching methods and approaches, changing the traditional teacher-centered teaching model into studentscentered teaching model for the purpose of guaranteeing students' subject position and teachers' leading role. We adopted teaching methods and approaches below:

\subsection{Project-Based Teaching}

Project-based teaching was one of most popular pedagogies applied in higher vocational schools, and now begins to be adopted by an increasing number of colleges and universities. This pedagogy takes projects as carriers. Guided by teachers, students deal with a project independently, ranging from gathering information, designing a plan, implementing a project to final evaluation. The striking feature of projectbased teaching is that projects form a consistent thread, teachers play a guiding role, and students are the subjects of learning, which establish a learning environment in which students can actively participate, automatically cooperate and hardly explore [9].

Every project offers a real application situation, and then provides some background knowledge involved in this project. According to the task which they will finish, students independently try to learn relevant knowledge, design plans and accomplish them. Let's take the project of making twisted-pair cables for example. Firstly, we will offer such an application situation-Some network cables are needed in order to help several computers in your dormitory to organize local area network. Try your best to make network cables! And then, relevant background knowledge will be pro-
Table 1. The content of practice of computer network.

\begin{tabular}{|c|c|}
\hline \multirow[t]{4}{*}{ Basic training } & Summary of Computer Network \\
\hline & Introduction of practical environment \\
\hline & Making twisted-pair cables \\
\hline & Foundation of Ethernet \\
\hline \multirow{8}{*}{$\begin{array}{l}\text { Network tech- } \\
\text { nique training }\end{array}$} & Configuration of switch \\
\hline & Configuration of VLAN on one switch \\
\hline & Configuration of VLAN through two switches \\
\hline & Communication among different VLAN \\
\hline & Configuration of router \\
\hline & Static routing \\
\hline & Dynamic routing \\
\hline & NAT configuration of router \\
\hline \multirow{4}{*}{$\begin{array}{l}\text { Server } \\
\text { configuration }\end{array}$} & Configuration of DHCP server \\
\hline & Configuration of WEB server \\
\hline & Configuration of FTP server \\
\hline & Configuration of DNS server \\
\hline \multirow{8}{*}{$\begin{array}{l}\text { Advanced pro- } \\
\text { ject training }\end{array}$} & Flow control by access control list \\
\hline & Configuration of firewall \\
\hline & Use of Sniffer \\
\hline & Analysis of network data packets \\
\hline & Simple network programming \\
\hline & Integrated wiring \\
\hline & Network integrated design training \\
\hline & Introduction of Internet of Things \\
\hline
\end{tabular}

vided. For instance, there should be an introduction to the involved tools such as twisted-pair, RJ-45 plugs, Wire pliers, Cable measurement instrument standards for making network cables, manufacturing methods and so on. Students first learn relevant knowledge and then start the project.

Project-based teaching can adequately encourage students to independently learn knowledge. Students are not passive knowledge-receivers any more. In order to finish the project, students will learn knowledge on their own initiative. Appling what they have learn, students will design and carry out their own plans and test the possibility of the plans. In this process, students' creative ability is well developed. Sometimes they can design several plans.

\subsection{Multi-Level Teaching Model}

The subject position of students requires us to consider differences among students' personality and aptitude. A onesize-fits-all policy should be abandoned. Multi-level teaching method extends different treatments to students of differ- 
ent levels of knowledge and aptitude. It offers different requirements for students of different levels, which makes top students be well fed and poor students stand easily. Multilevel teaching is a method which really accords with cognitive rules [10].

There are basic requirements and extended requirements for every practical project. The basis requirements contain content which should be necessarily accomplished. This part of content, oriented towards all the students, is relatively simple and focuses on basic knowledge and techniques. The extended requirements contain optional content, oriented towards students of high ability, focuses on extended knowledge. For instance, in the project of dividing VLAN on switch, the basic requirements for students are to make students master how to divide VLAN on one switch and how to realize VLAN across switches. Extended requirements focus on how to realize the communication among different VLAN after students divide VLAN. In the project of using access control list to control network flow, the basic requirements are to make students master how to control network flow by the standard access control list, while extended requirements are to make students learn how to realize fine-grained control by extended access control list.

Multi-level teaching meets different needs of students of different level, and consequently helps them to develop their creative and practical ability by arousing students' learning activity.

\subsection{Reforming Assessment Methods}

The original single assessment model which only values experiment results should be reformed. Diversified assessment system is introduced. Among one hundred percent, attendance takes up $10 \%$; finishing basic requirements takes up 50\%; finishing extended requirements takes up 20\%; cooperation and practice take up 10\%; and creativity takes up $10 \%$. In such an assessment system, assessing attendance will urge student to participate in practical learning; different layer of requirements not only take ordinary students into account, but encourage students to finish the higher requirements actively and creatively; assessing cooperation and practical ability can examine cooperation among students and practice of assigned tasks; assessing creativity can encourage students to display inventiveness in solving problems. This kind of assessment system can foster students' activity in classroom, ability of autonomous learning, cooperation, and most of all, it can improve practical ability and creativity.

\subsection{Increasing Out-of-Class Integrated Practice}

Considering the limited period of practice course, we increase the link of course design to well cultivate students' ability of practice and creativity. In this link, we provide a couple of big projects from which students can choose. These projects need the integrated application of the previous learning techniques and they also offers a chance to extendedly learn new techniques and application. Besides, in order to meet the needs of some students who are interested in network technology, we arrange, in spare time, some optional practice for students. By way of discovering problems and solving problems, students extend their knowledge and improve their creative ability in the process of active learning.

\subsection{Providing Network Learning Platform}

In order to extend learning from in class to outside class, we establish the platform for computer network teaching resources within campus network. On this platform, syllabus, courseware, practice projects, extended knowledge, BBS and so on are provided, which supplies students and teachers a chance to interact with each other and provides an environment for students to learn independently. Students can attain the relevant knowledge in and outside class with the help of this platform, and they can also communicate with teachers and classmates online. Therefore, this teaching network learning platform suits students of different learning habits and levels, and it provides students an ideal digital leaning environment, encouraging them to independently learn and extend their learning.

\section{CONCLUSION}

The cultivation of versatile talents is the reform of teaching idea, which aims at improving students' actual working ability, professional quality and creative ability, fostering talents which can meet the needs of economic development and helping students to hunt for a satisfactory job after they graduate. Taking the course of Computer Network as a backing, practice teaching as a breakthrough, we manage to explore an efficient method to cultivate versatile talents and this approach has brought good effect. We wish we would set an example in terms of fostering teaching reform in computer science and improving the employment ability of students majoring in computer science.

\section{CONFLICT OF INTEREST}

The authors confirm that this article content has no conflict of interest.

\section{ACKNOWLEDGEMENTS}

This work is supported by the Education and Teaching Reform Project of Jining Medical University in 2014 (No.14056).

\section{REFERENCES}

[1] J. Li, and Y.Y. Qiu, "The computer professional compound talents training mode and practice”, Computer Engineering \& Science, vol. 33, no. A1, pp. 86-88, 2011.

[2] K. J. Zhang, Z. Z, "The cause of computer science graduates' current employment status and the cultivation method of core competition", Computer Education, 2010, vol. 2010, no. 20, pp. 16 19.

[3] X.H. Lu, "Discussion on the higher education reform by employment difficulties for computer majors", Computer Education, vol. 2010, no. 18, pp. 34-37, 2010.

[4] F. Sheng, "Discussion on computer network teaching reform based on employment-oriented", Computer CD Software and Applications, vol. 2012, no. 4, pp. 232-233, 2012.

[5] M. Wang, and Y.F. Wang, "Exploration of computer network experiment teaching system based on innovation ability training", Modern Computer, vol. 2013, no. 9, pp. 44-47, 2013.

[6] H. Xie, X. P. Wu, and L. H. Li, "Using NS2 to construct computer network experiment curriculum system", Research and Exploration in Laboratory, vol. 29, no. 1, pp. 74-76, 2010. 
[7] Q.Z. Yan, and T.F. Ye, "Research of the experimental teaching of computer networks simulation based on OPNET modeler", Journal of Jimei University, vol. 15, no. 3, pp. 111-114, 2014.

[8] J.Q. Hu, "An integrate case of computer network practice based on red-giant computer network laboratory", Computer Knowledge and Technology, vol. 6, no. 17, pp. 4619-4620, 2010.
[9] J.L. Yang, and X.S. Li, "Application of project teaching method in computer course in medical universities", Computer Education, vol. 2010, no. 18, pp. 105-107, 2010.

[10] X.L. Wang, "Construction of hierarchical computer network curriculum system", Computer Education, vol. 2011, no. 6, pp. 20-23, 2011.

Received: September 16, 2014

Revised: December 23, 2014

Accepted: December 31,2014

(C) Wang and Kong; Licensee Bentham Open.

This is an open access article licensed under the terms of the Creative Commons Attribution Non-Commercial License (http://creativecommons.org/licenses/by-nc/3.0/) which permits unrestricted, non-commercial use, distribution and reproduction in any medium, provided the work is properly cited. 